\title{
Perineural Invasion in Adenoid Cystic Carcinoma of the Salivary Glands: Where We Are and Where We Need to Go
}

\author{
Xiaohao Liu, Xiaojun Yang, Chaoning Zhan, Yan Zhang, Jin Hou* and Xuemin Yin* \\ Department of Oral and Maxillofacial Surgery, Nanfang Hospital, Southern Medical University, Guangzhou, China
}

Adenoid cystic carcinoma of the salivary gland (SACC) is a rare malignant tumors of the head and neck region, but it is one of the most common malignant tumors that are prone to perineural invasion (PNI) of the head and neck. The prognosis of patients with SACC is strongly associated with the presence of perineural spread (PNS). Although many contributing factors have been reported, the mechanisms underlying the preferential destruction of the blood-nerve barrier (BNB) by tumors and the infiltration of the tumor

OPEN ACCESS

Edited by:

Victor C. Kok

Asia University, Taiwan

Reviewed by:

Anxun Wang,

First Affiliated Hospital of Sun Yat-Sen

University, China

Moran Amit,

University of Texas MD Anderson

Cancer Center, United States

*Correspondence:

Jin Hou

houjin@smu.edu.cn

Xuemin Yin

yinxuemin1983@163.com

Specialty section:

This article was submitted to

Head and Neck Cancer,

a section of the journal

Frontiers in Oncology

Received: 23 April 2019

Accepted: 13 July 2020

Published: 18 August 2020

Citation:

Liu X, Yang X, Zhan C, Zhang Y, Hou J and Yin $X(2020)$ Perineural Invasion in

Adenoid Cystic Carcinoma of the

Salivary Glands: Where We Are and

Where We Need to Go.

Front. Oncol. 10:1493.

doi: 10.3389/fonc.2020.01493 microenvironment by nerve fibers in SACC, have received little research attention. This review summarizes the current knowledge concerning the characteristics of SACC in relation to the $\mathrm{PNI}$, and then highlights the interplay between components of the tumor microenvironment and perineural niche, as well as their contributions to the PNI. Finally, we provide new insights into the possible mechanisms underlying the pathogenesis of $\mathrm{PNI}$, with particular emphasis on the role of extracellular vesicles that may serve as an attractive entry point in future studies.

Keywords: adenoid cystic carcinoma, salivary glands, perineural invasion, tumor microenvironment, perineurium barrier

\section{INTRODUCTION}

There are three main ways by which tumors spread: direct invasion into adjacent tissues, hematogenous metastasis, and lymphatic spread; however, perineural invasion (PNI) is considered a fourth route of dissemination, which can be of great significance in the invasion and metastasis of tumors. PNI has been emerging as a significant pathologic feature of many malignant tumors, including those of the pancreas, prostate, colon, rectum, and head and neck, etc. (1). There is a high incidence of PNI in many of these malignancies, and this feature has become an indicator of poor prognosis and is associated with reduced survival (2).

SACC is one of the most common malignant salivary gland tumors, comprising $10 \%$ of all salivary gland neoplasms, which is characterized by PNI, strong invasiveness, and hematogenous metastasis (3). With respect to the primary site of tumor, there are various anatomical locations although most of them arise from the small salivary glands (75.4\%). In the major salivary glands, $53.3 \%$ of tumors involve the submandibular gland, while $46.7 \%$ involve the parotid gland (4). Moreover, SACC comprises $4 \%$ of all salivary gland tumors, as well as $7.5 \%$ of all epithelial salivary gland malignancies (5). SACC generally has an indolent clinical course; nevertheless, advanced tumors may cause pain and/or nerve paralysis, as SACC has a tendency to directly invade the adjacent nerve sheaths close to the primary tumor and spreads along the nerve, a condition referred to as PNI and perineural spread (PNS), respectively. 
The 5-year survival rate is relatively high in SACC patients, in contrast with the poor prognosis associated with other epithelial malignancies (5); however, the recurrence rate is also high in SACC, and closely related to PNI (6). Earlier studies suggested that lymph node involvement is uncommon in SACC, but Amit et al. found that the incidence of occult neck metastases among patients with ACC is $17 \%$ by retrospective multicentered study (7). Distant metastases are most frequently detected in the lungs, followed by bones, liver, skin, and breasts. The diagnostic transfer rate of SACC ranges from 25 to 55\% (8). Distant metastases from SACC primary tumors can remain asymptomatic for long periods of time (6). Even when the tumor have been completely removed, with no recurrence at the primary tumor site, SACC still has a high tendency to spread to the other body parts over a period of time, which is the major cause of death in patients with SACC. However, outcome in SACC is significantly associated with the involvement of margins. Amit et al. analyzed the data of 507 patients with adenoid cystic carcinoma, and suggested that the positive edge is related to the worst outcome, while the negative edge and the near edge are related to the improved result, but not the distance of the tumor (9).

PNI is significantly correlated with both distant metastasis and unfavorable disease outcomes (10). Notably, in one series of patients with clear surgical margins, $80 \%$ of patients harboring PNI eventually progressed to local or distant recurrence, compared with only $27 \%$ of patients without PNI (11). Given that microscopic invasion of the cancer cells into the surrounding nerve tissues is assumed to occur via the "path of least resistance" it is often a challenge for a surgeon to detect and determine the resection border during surgery. Due to its microscopic size, CAT (computerized axial tomography), and PET (positron emission tomography) scans may also fail to detect PNI. However, Singh et al. have described that MRI can observe the enlargement and enhancement of the image of nerves that have been invaded by the tumor. This can assess whether the tumor has nerve invasion to a certain extent due to its high soft tissue contrast. Compared with CT, MRI is more sensitive to detect perineural proliferation but CT is complementary to MRI and can be used to assess local skeletal changes (12). There have been several studies concerning the statistical association between margin status and PNI. One such study demonstrated that PNI was the strongest prognostic indicator in their series of patients with SACC; however, no specific $p$-value was presented to support their claims (8). In another study, Jang et al. demonstrated that SACC with PNI subsequently progressed to metastasis, while no distant metastasis was observed in those without PNI (13). Multivariate analysis revealed that PNI was a significant predictive factor in distant metastasis (14). These results indicate that PNI potentiates distant metastatic progression, thus influencing patient outcomes.

Given that PNI is closely related to the prognosis of SACC patients, an in-depth exploration of the underlying mechanisms is needed to identify predictors of this condition, and screen out markers that predict tumor prognosis, which may contribute to the development of novel targeted drugs and reduction in recurrence risk in patients with SACC.
Currently, there are two prominent theories on the pathogenesis of PNI: one is the "path of low resistance" and the other is reciprocal signaling interactions. Due to the anatomical proximity between the salivary glands and some cranial nerves, such as the facial nerve, trigeminal nerve, hypoglossal nerve, and glossopharyngeal nerve, the salivary glands have plenty of neural tissues. Some researchers hypothesize that the tumor cells grow along the eural tissues. Some res" which serves as a conduit for their distant migration, whereas the other researchers believe that there are certain factor-based interactions between tumor cells and nerves, which provide a microenvironment suitable for tumor cell growth and proliferation around the nerves (15). In addition, many recent studies have suggested that cell signaling factors contribute to the interaction between tumor and nerve tissue; for example, by increasing the affinity of tumor cells for neural tissue (8). At present, the occurrence of neurotropic invasion is widely considered to involve a variety of microenvironmental regulatory factors, including chemokines and their receptors, brain-derived neurotrophic factor (BDNF) family proteins and their receptors, nerve growth factor (NGF) family proteins and their receptors, as well as matrix metalloproteinases (MMPs) and PNI-related cells (such as macrophages, astrocytes, and Schwann cells) (16).

In this review, we summarize the current knowledge concerning the characteristics of SACC in relation to the PNI, and then highlight the interplay between components of the tumor microenvironment and perineural niche, as well as their contributions to the PNI. Finally, we provide new insights into the possible mechanisms underlying the pathogenesis of PNI, with particular emphasis on the role of extracellular vesicles that may serve as an attractive candidate pathways in future studies.

\section{ANATOMICAL FACTORS OF SACC PERINEURAL INVASION}

PNI is a common clinical manifestation of various tumors, including pancreatic cancer, gastric cancer, prostate cancer, and head and neck cancer (17-20). PNI is distinct from PNS. Specifically, PNI is characterized at the microscopic level by the confined invasion of the tumor mass into nerves, while PNS refers to the clinico-radiological findings of distant distribution via the perineural space, or within the neural sheath and nerve itself (21). In 2009, Liebig et al. proposed that PNI of tumor cells can be defined as tumor cells near peripheral nerve fibers, surrounding them by at least $33 \%$, or tumor cells infiltrating into any layers of nerves-endoneurium, perineurium, and epineurium (1). However, some scholars have divide neural invasion into epineural association, perineural invasion, and endoneural invasion based on the scope of neural invasion. Among them, endoneural invasion is an independent predictor of poor prognosis $(22,23)$.

The normal peripheral nerve consists of three layers of connective tissue with differing characteristics. The epineurium, the outermost fascial layer, is composed of the dense irregular connective tissues that binds individual nerve fascicles into a nerve trunk; the endoneurium is the innermost layer 
surrounding axons along with Schwann cells (SCs); the perineurium, the middle layer, is made of layers of flattened cells forming laminar structures wrapping around single nerve fascicles. Epineurium surrounds the entire nerve trunk, thus contributing to the tensile strength of the nerve, but it does not provide a barrier function. The existence of the tight junction (TJ) structures in perineurium and endoneurial vasculature forms the peripheral nerve barrier $(24,25)$. These structures have been recognized as shielding barriers to the paracellular diffusion of certain molecules and ions $(26,27)$. Recently, an increasing number of studies have indicated that TJ may act as a barrier against cancer invasion and metastasis (28-30). Therefore, we speculate that a possible explanation of PNI of malignant tumors may be that when tumor cells begin to invade peripheral never, the TJ structure of perineurium must first be disturbed and dismantled to facilitate penetration of the tumor cells.

\section{THE PERINEURAL NICHE AND TUMOR MICROENVIRONMENT IN PNI}

A study of neurological invasion, involving nerve cells, tumor cells, and stromal cells, investigated the neurotropic characteristics of prostate cancer and reported that these cell types could respond to secretory or intracellular cytokines, leading to neurologic attacks by tumors, in which axon growth is an important step (1). Axonal growth is complex and involves multiple factors, the most studied of which include chemokines and their receptors, the GDNF family and their receptors, and the NGF family and their receptors, along with matrix metalloproteinases (MMPs) and PNI-related cells (Table 1). Schwann cells are closely associated with the process of neural invasion, both prior to and during tumor invasion, and are therefore important for the initiation and development of PNI (16).

\section{Perineurial Cells}

A transmission electron microscopy study demonstrated that the thickness of the perineurium is $\sim 10-25$ microns, and that it consists of 8-15 concentric layers of flat perineurial cells (44). Each perineurial cell layer comprises flattened cells, linked by special connections that provide a barrier to diffusion. In addition, some intraneural blood vessels, with diameters of $\sim 6-$ 10 microns, were found close to the axons; these were composed of 6-8 layers of endothelial cells and formed a blood-neural barrier (BNB) with the perineurium (31). Previous studies have demonstrated that perineurial cells can control the integrity of the BNB by secreting various cytokines and growth factors, such as VEGF, BDNF, GDNF, bFGF, and Angiopoietin-1. Moreover, certain factors secreted by perineurial cells can also contribute to the regulation of the tight junction protein, claudin-5, in BNB endothelial cells, thus strengthening the barrier function of the BNB (32). These findings suggest that various factors in the neural microenvironment may regulate the BNB barrier function by affecting the tight junctions between perineurium cells.

Hence, it is important to fully understand the BNB that may represent the first line of defense against tumor PNI, in
TABLE 1 | Mediators in the perineural niche and tumor microenvironment in PNI.

\begin{tabular}{|c|c|c|c|}
\hline Factors & $\begin{array}{l}\text { Interrelated } \\
\text { factors }\end{array}$ & Role in PNI & References \\
\hline $\begin{array}{l}\text { Perineurial } \\
\text { cells }\end{array}$ & Tight junctions & $\begin{array}{l}\text { The tight connections in the } \\
\text { perineurial cells are the main } \\
\text { players of the neural barrier } \\
\text { function }\end{array}$ & $(26,27)$ \\
\hline \multirow{3}{*}{$\begin{array}{l}\text { Other } \\
\text { PNI-related } \\
\text { cells }\end{array}$} & Schwann cells & $\begin{array}{l}\text { Interact with preneoplastic } \\
\text { cells }\end{array}$ & (31) \\
\hline & TAMs & Positive correlation with PNI & $(32,33)$ \\
\hline & Stellate cells & $\begin{array}{l}\text { Induce the proliferation of } \\
\text { cancer cell and associated } \\
\text { with the generation of } \\
\text { neuronal plasticity }\end{array}$ & $(34,35)$ \\
\hline Nerve fibers & NGF secretion & $\begin{array}{l}\text { Associated with NGF } \\
\text { production and lymph node } \\
\text { invasion in cancer }\end{array}$ & (36) \\
\hline \multirow[t]{2}{*}{$\begin{array}{l}\text { NGF family } \\
\text { and receptors }\end{array}$} & NGF-TRKA & $\begin{array}{l}\text { Positive correlations with } \mathrm{PNI} \\
\text { and poor prognosis in cancer }\end{array}$ & (37) \\
\hline & BDNF-TRKB & $\begin{array}{l}\text { Significantly correlated with } \\
\text { advanced clinical stage, poor } \\
\text { prognosis, PNI, vascular } \\
\text { invasion, and distant } \\
\text { metastasis } \\
\text { in SACC; Have a role in the } \\
\text { EMT process in SACC }\end{array}$ & $(38,39)$ \\
\hline $\begin{array}{l}\text { GDNF family } \\
\text { and receptors }\end{array}$ & $\begin{array}{l}\text { GDNF-GFR } \alpha 1 \text { - } \\
\text { RET }\end{array}$ & Induce tumor cell migration & (40) \\
\hline \multirow[t]{2}{*}{$\begin{array}{l}\text { Chemokines } \\
\text { and receptors }\end{array}$} & CXCL12/CXCR4 & $\begin{array}{l}\text { Significantly correlated with } \\
\text { PNI and increased secretion } \\
\text { of MMPs }\end{array}$ & $(41)$ \\
\hline & CX3CL1/CX3CR1 & $\begin{array}{l}\text { Significant positive } \\
\text { correlation with } \mathrm{PNI} \text { and } \\
\text { promote tumor migration and } \\
\text { invasion }\end{array}$ & (42) \\
\hline MMPs & $\begin{array}{l}\text { MMP-2 and } \\
\text { MMP-9 }\end{array}$ & $\begin{array}{l}\text { Degradation of ECM and } \\
\text { basement membrane and } \\
\text { involved in NGF-TRKA } \\
\text { signaling and GDNF-RET } \\
\text { pathway }\end{array}$ & (43) \\
\hline
\end{tabular}

order to develop new options for the diagnosis and treatment of tumor PNI.

\section{Other PNI-Related Cells}

Schwann cells (SCs) are the most common type of cells in peripheral nerves and, along with glial cells, play a key role in nerve repair and regeneration (33). Recent evidence suggests that the affinity of SCs for specific types of gastrointestinal cancer, as well as their migration in cancer, might precede any invasion of the neural environment, and thus play a role in PNI (34).

Tumor-associated macrophages (TAMs) interact with tumor cells and can modulate tumor growth, proliferation, metastasis, and prognosis via a series of cytokines, which are essential components of the tumor microenvironment (35). Endogenous macrophages also present molecules that participate in the balance and regeneration of peripheral nerves. Moreover, the production of GDNF by endothelial macrophages during PNI 
is promoted by CSF-1 secretion by pancreatic cancer (PC) cells. Notably, a clinical study has reported a correlation between macrophages and PNI (45).

Stellate cells are myofibroblasts, which can be activated by hypoxia, inflammation, and interactions with precancerous cells and cancer cells. Activated stellate cells promote PNI in pancreatic carcinoma (PC), and are a key contributor to connective tissue hypertrophy (36). The activation of stellate cells promotes the localized growth of PC in co-cultures of tumor cells and pancreatic astrocytes, as well as the propagation of PC cells in an in-situ model of PC (46).

\section{Nerve Fibers}

Axons, also called nerve fibers, are thread-like projections that carry electrical signals between nerves and receptors in the skin, muscles, joints, and internal organs (47). Emerging evidence has shown that the invasion of tumor is dependent on the axon structure, and denervation can inhibit the growth and metastasis of tumor (48). Pundavela et al. have found that the presence of nerve fibers in breast cancers is relevant to lymph node invasion and the production of biologically active NGF (49) that can stimulate neuron outgrowth (axonogenesis or neo-neurogenesis), thus promoting PNI (50). Further, in order to investigate interactions between nerve fibers and tumor cells, Liu et al. established an in vitro model of PNI by coculturing rat root ganglia (DRG) and human pancreatic cancer cell line (MIA PaCa-2). They found that these cancer cells could stimulate the outgrowth of neurites from DRG. Of note, while these neurites tended to migrate toward pancreatic cancer cell colonies, cancer cells also exhibited a trend of migrating along the contacting neurites simultaneously (37). This indicates that there may exist a reciprocal regulation loop between nerves and cancer cells. Moreover, it has been suggested that higher densities of nerve fibers within tumors were closely associated with poorer clinical outcomes in prostate cancer patients. However, in a mouse model of gastric cancer, the incidence and progression of tumors could be significantly reduced at denervation sites (either surgically or pharmacologically treated) of the stomach (51), again indicating a crucial role of nerves in the growth and progression of tumors (52). Cancer exosomes induced the innervation of the tumor and the exosomes from patients with head and neck cancer had neurite outgrowth activity, while the exosomes from the healthy control group did not (53). Nonetheless, due to the complexity of the tumor microenvironment, the role of nerve fibers in the tumor microenvironment is so far still an understudied research area that warrants further investigation.

\section{NGF Family and Receptors}

The nerve growth factor (NGF) family mainly consists of neurotrophin 3 (NTF3), NGF, neurotrophin 4 (NTF4), and brainderived neurotrophic factor (BDNF) (54). By binding to diverse receptors, NGFs can trigger multiple signaling pathways, which function in the regulation of cell growth, apoptosis, and neuronal formation. Besides, it not only has many important regulatory functions for the survival, growth and differentiation of nerve cells in the peripheral and central nervous system, but also plays a role in regulating the synthesis of neurotransmitters and neuropeptides in sympathetic and sensory nerve cells effect (38). Each NTF binds to tropomyosin-receptor kinases (TRK) receptor with high affinity, or to p75 neurotrophin receptor (p75NTR), with low affinity; NGF binds with high affinity to TRKA; BDNF and NTF4 both bind to TRKB receptors; and NTF-3 binds preferentially to TRKC (39).

Elevated NGF levels have been identified in PC, relative to adjacent normal tissues, with particular over-expression of TRKA in peripheral nerves. Additionally, there is a significant positive correlation between the expression of NGF and TRKA and the incidence of neural invasion, as well as a poor prognosis, in PC and cell co-culture models of PC (55).

BDNF is thought of as "brain fertilizer," due to its potential roles in promoting the survival of existing neurons, as well as inducing the proliferation and differentiation of new neurons and synapses (56). However, BDNF and TRKB have been recently reported to be involved in the malignant progression of multiple cancers, including colon cancer, hepatocellular carcinoma, prostate cancer, and oral squamous cell carcinoma $(40,57)$. Jia et al. demonstrated that higher expression levels of BDNF and TRKB were significantly correlated with advanced clinical stage, poor prognosis, PNI, vascular invasion, and distant metastasis of SACC (41). Collectively, these findings implicate the involvement of $\mathrm{BDNF} / \mathrm{TRKB}$ axis in $\mathrm{PNI}$ progression of SACC (58). Furthermore, the BDNF/TRKB axis is also reported to have a role in the epithelial-mesenchymal transition (EMT) process in SACC. And the study by Mei Zhang et al. proposed a correlation between PNI and MIF expression that MIF may promote the PNI of SACC by participating in cytoskeletal reorganization and pseudopod formation induced by Schwannlike cell differentiation of EMT and SACC cells (59). Despite the limited number of studies concerning the association between EMT and PNI, EMT is likely to play an invasive critical role in PNI progression, given the enhanced migration and abilities of cancer cells after EMT (42). Notably, there is a significant negative association between TRKB and E-cadherin expression in SACC specimens, supporting a potential role of the BDNF/TRKB axis in EMT during the development of PNI in SACC (58).

Recently, new evidence suggests that the PIK3K/Akt signaling pathway is associated with PNI in ACC. It has been found that NGF can activate PI3K/AKT pathway through phosphorylating AKT in SACC, thereby potentially stimulating scattering and migration of tumor cells which enhances the progression of PNI (60). Additionally, animal experiments have also shown that a high expression of Akt3 serves as a driving factor of salivary gland tumor progression (43). In addition, the NT-3/TrkC axis promotes the progression of PNI and the poor prognosis of SACC by regulating the interaction between SACC cells and SC. Interrupting the interaction between SACC cells and SC by blocking the NT-3/TrkC axis may be an effective strategy for anti-PNI therapy in SACC (61).

\section{GDNF Family and Receptors}

The GDNF family, derived from the glial cell line, a group of neurotrophin polypeptides, which is comprises four members: neurturin (NRTN), persephin (PSPN), artemin (ARTN), and glial 
cell line-derived neurotrophic factor (GDNF). The GDNF family is secreted by neural tissues and binds with relevant receptors to trigger the differentiation of neuronal cells of the central and peripheral nervous systems. It works mainly in a paracrine manner and plays an important role in the development and maintenance of the central and peripheral nervous systems, kidney morphogenesis and sperm formation (42). GDNF, NRTN, ARTN, and PSPN bind to GFRA1 (GDNF family receptor alpha1), GFRA2 (GDNF family receptor alpha-2), GFRA3 (GDNF family receptor alpha-3), and GFRA4 (GDNF family receptor alpha-4), respectively (42). It has been suggested that PNI may be mediated through the secretion of GDNF by nerves and further activation of tumor cell surface Ret proto-oncogene (RET) receptors. GFRA1 functions as a co-receptor with RET, both of which are required for GDNF interaction. He et al. have found that DRG neurons can release soluble GFRA1 that may enhance RET phosphorylation and tumor cell migration toward GDNF, even when tumor cell expression of GFRA1 is absent (62). Moreover, in another previous study, a high level of GDNF expression was detected in SACC cells and adjacent nerve fibers, which was demonstrated to be associated with an increase in matrix-degradation during PNI progression (63).

\section{Chemokines and Receptors}

Chemokines and their receptors have critical roles in the growth and invasion of tumor cells. CXCL12/CXCR4 (C-X-C Motif Chemokine Ligand 12/C-X-C Motif chemokine receptor 4) signal transduction is a candidate for participation in intertumor interstitial interaction and has various functions, such as the regulation of cell proliferation, invasion, EMT, metastasis, and angiogenesis in multiple types of malignancy (64). In PC cells, MMP-9 secretion in response to CXCR4 stimulation may contribute to the process of PNI, via enhancement of extracellular matrix (ECM) degradation (65). Furthermore, CXCL12 significantly increases the NGF expression in PC cells and promotes neuronal regeneration by binding to the CXCR4 receptor. An in vitro model showed that the elimination of the CXCL12/CXCR4 signaling pathway led to the suppression of chemotactic migration between PC cells and nerve cells; by blocking the CXCL12/CXCR4 pathway, PC cell neurotropism decreased significantly (66). Therefore, CXCL12/CXCR4 signaling is significantly correlated with PNI. Moreover, Thomas et al. performed CXCR4 immunohistochemical staining and semiquantitative scoring on the tumor tissue of 73 head and neck adenoid cystic carcinoma (AdCC) patients and found that high CXCR4 expression in AdCC is associated with an increased risk of local recurrence (67).

CX3CL1 (C-X3-C Motif Chemokine Ligand 1) is found to be abundantly produced and released by neurons. An elevated expression level of its receptor, CX3CR1 (C-X3-C Motif Chemokine receptor 1), has been implicated in the development of PNI and earlier recurrence of numerous cancers, such as PC, gastric cancer, and prostate cancer (68-70). Equally important, both in vitro co-culture and in vivo PNI models demonstrated that nerve cells, including Schwann cells and neurons, express CCL2 (C-C motif chemokine ligand 2) which capable of inducinge the migration of CCR2 (C-C Motif
Chemokine receptor 2) expressing cancer cells toward these nerves, ultimately promoting PNI progression $(16,71,72)$. Role of CX3CR1/CX3CL1 axis in primary and secondary involvement of the nervous system by cancer.

\section{Matrix Metalloproteinases (MMPs)}

MMPs are a family of endopeptidases responsible for the degradation of the ECM and tissue remodeling. The expression of certain types of collagen has been confirmed in peripheral nerves, including collagen IV, the main component of the basement membrane of Schwann cells (73). MMP2, MMP7, MMP9, and all type IV collagenases secreted in response to NGF or GDNF, are likely to be involved in PNI (74). In addition, the overexpression of MMP2 by myofibroblasts has been documented in SACC, exhibiting high-grade PNI.

These results indicate that nerves can indeed provide an appropriate environment for tumor growth and the reciprocal interaction positively influence the growth of both nerves and tumors. Although the accuracy of a "path of low resistance" theory is still up for debate today, emerging evidence indicates that the PNI phenomenon is more like a process of active invasion rather than simple diffusion.

\section{PNI MODELS}

As mentioned above, PNI is very closely correlated with the prognosis of patients with SACC. Although it was discovered over a century ago, we still know little about the molecular mechanisms involved in the PNI process. In vitro models of these complicated disease processes are very difficult to create. To gain a comprehensive understanding of the contribution of a series of soluble factors to PNI, some researchers have attempted to create in vitro models, using highly controlled experimental settings. For example, Ayala et al. established an in vitro model, where murine DRGs were co-cultured with prostate cancer cells in Matrigel (75). Once suspended in Matrigel, the axons from the DRGs could spread in all directions. These axons grew toward tumor colonies and were gradually invaded by cancer, which mimics the clinical observation of the typical centripetalism of PNI spread. Using this model, Ayala et al. first described the symbiosis exhibited between cancers and nerves in PNI, in which both gain a growth advantage when co-cultured (76). Although the use of this model can better mimic the invasion of tumor cells into nearby nerves, it is not able to replicate the highly complex microenvironment of in vivo perineural niches. Of note, Deborde et al. used Live-imaging technology to investigate the interactions between cancer cells and Schwann cells in vitro coculture and in vivo murine models of PNI. They found that neither soluble factors secreted by Schwann cells, nor empty tunnels established by Schwann cells were capable of mediating cancer cell invasion, whereas physical contact between Schwann living cells and cancer cells facilitated invasion process. This model provides a new insight into the analysis of the complex in vivo characteristics of Schwann cells in enhancing PNI (77). Currently, a murine sciatic nerve model is widely used to explore PNI; tumor cells are injected into the distal sciatic nerve of mice to establish an in vivo PNI model. Under gross observation, the sciatic nerve 
is seen enlarged; histologically, tumor infiltration of the sciatic nerve can be visualized by hematoxylin and eosin staining and immunohistochemistry of pathological tissue sections. Notably, the effects of PNI can be analyzed by monitoring hind limb motor performance, such as the hind paw width of the mice, as well as sciatic neurological score. More importantly, this model, with the genetic manipulation of mice and/or use of different types of cancer cells, can be applied to study cellular and molecular mechanisms involved in PNI and the effects of therapeutic agents on neural invasion (78). These emerging models of PNI strongly suggested there is an extensive signaling interaction between the nerves and invading tumor cells. Recently, an in vivo PNI model has been developed to unravel molecular mechanisms of nerve-tumor interactions. Briefly, rat DRGs are transplanted onto the chick embryo chorioallantoic membrane, followed by the transplantation of human head and neck squamous cell carcinoma (HNSCC) cells adjacent to the DRG. This system can replicate a pro-angiogenic tumor microenvironment observed in carcinogenesis, where the newly formed vasculature provides nourishment for both DRGs and tumor cell grafts (79).

In the past few decades, three-dimensional (3D) printing technology has received widespread attention. Now 3D scaffolds fabricated by $3 \mathrm{D}$ bioprinting of biomaterials (bioinks) can be used for the regeneration and reconstruction of complex tissues and organs. Likewise, printed 3D tumor models have also been developed to simulate the in vivo tumor microenvironment (80). For instance, using 3D projection printing, an in vitro $3 \mathrm{D}$ micro-chip in a hydrogel was built, with the objective of simulating $3 \mathrm{D}$ vascular morphology of in vivo microenvironment, by which the behavior of both cancer and non-cancer cells can be monitored and analyzed (81). In addition, Valentina et al. reported that $3 \mathrm{D}$ bioprinting, combined with induced pluripotent stem cells (iPSCs) could effectively control the spatial distribution of cells (e.g., neurons); thus creating a more reliable in vitro model (82). Although the applications of this technology in the construction of in-vitro 3D tumor and neural tissue models are, so far, in the research stage, they provide some new insights into the study of the underlying mechanisms of PNI pathogenesis and progression.

\section{POSSIBLE MECHANISM OF PNI AND CONCLUSION}

Due to its insidious onset, its susceptibility to PNI, and high recurrence rates, SACCs are common malignant neoplasms of head and neck tumors. Furthermore, PNI is closely related to patient prognosis. Although many studies have investigated the mechanisms underlying $\mathrm{PNI}$, the precise details remain unclear. In recent years, researchers have begun to investigate the concept that nerves can reciprocally facilitate cancer invasion and progression (83), representing a paradigm shift in our understanding of the mechanism of PNI. Based on current research, we consider that although anatomical factors, cells, nerve growth factors (NGF, BDNF, etc.), chemokines in the tumor microenvironment are involved in the development of

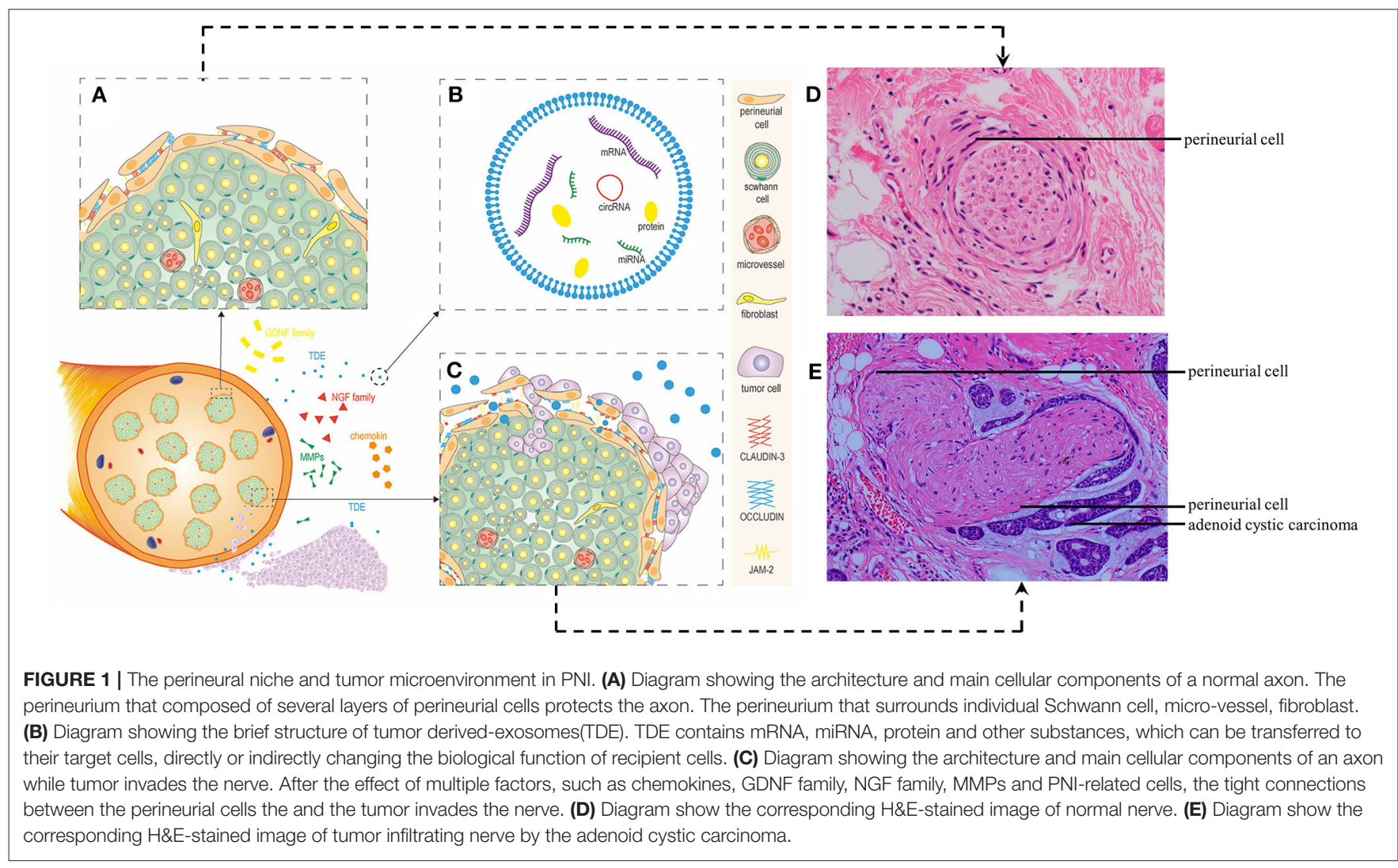


PNI, there are other factors that may also contribute to PNI, such as extracellular vesicles (EVs) derived from tumor cells, or other cells in tumor microenvironment and perineural niches (Figure 1).

Exosomes, known as the smallest subgroup of EVs, are secreted by cells when multivesicular bodies (MVBs) fuse with the plasma membrane (84). Many previous studies have shown that not only tumor cells produce more exosomes than normal cells, but also tumor-derived exosomes (TDE) containing a diverse set of proteins, mRNA, miRNA, and lipids, can "educate" interstitial cells, endothelial cells, inflammatory cells, and immune cells, in order to regulate the tumor microenvironment and promote tumor growth, invasion, metastasis and angiogenesis $(53,85)$. Melo et al. (86) found that breast cancer cells can produce mature exosomal miRNAs via a non-cell-dependent pathway, which regulates the phenotype of normal epithelial cells and accelerate their proliferation, and can also be used to generate tumors in nude mice. The development of distant metastases requires primary tumors to break through the basement membrane and penetrate the lymphatic or vascular circulation. Notably, invasive precancerous epithelial cells can overcome this physical constraint by obtaining invasive and migration properties through EMT. Taverna et al. (87) found that exosomal miR-126 derived from chronic myeloid leukemia cells can alter the adhesion and migration ability of recipient cells. Moreover, other studies have confirmed that exosomal miR-105 is specifically expressed and secreted by metastatic breast cancer cells via exosome secretion, and can be transferred to endothelial cells, thereby facilitating cancer metastasis by disrupting the vascular endothelial barrier (88). Hoshino et al. found that tumor-derived exosomes could direct organ-specific metastasis via exosomal integrins (ITGs) (89), based on their intrinsic organotropic homing ability and capacity of initiating premetastatic niche formation at foreign sites. Moreover, not only can tumor cells alter the cellular physiology of both surrounding and distant microenvironment through TDE, but other cells in tumor/pre-metastatic microenvironment can also target tumor cells via exosomes, leading to the co-evolution of tumor cells and their microenvironment during tumor dissemination and metastatic outgrowth. A recent study demonstrated that exosomes released by astrocytes could induce an intercellular transfer of PTEN-targeting microRNAs to metastatic tumor cells (90). This finding indicates that exosomes from non-neoplastic cells may also promote the adaptation of disseminated tumor cells to target organs, suggesting the involvement of dynamic bidirectional crosstalk in the pre-metastatic microenvironment. Many previous studies have shown that EVs participate in the dissemination of numerous primary cancer cells, including breast cancer, gastric cancer, colon cancer, liver cancer, malignant melanoma, etc. (91). For instance, one recently published study reported that head and neck tumor-derived exosomes could induce tumor innervation that was enhanced by the exosomepackaged axonal guidance molecule, EphrinB1. This indicates that interventions targeting exosome biogenesis and release may be of therapeutic value against PNI (92). Of particular note, in our previous study, we found that the exosomes derived from the adenoid cystic carcinoma cell line (SACC-83) could be uptaken by human umbilical vein endothelial cells (HUVECs), and destroyed the vascular endothelial barrier (93). Considering that primary tumor-derived EVs can destroy epithelial cell tight junction assembly to induce EMT, and trigger vascular permeability to allow cancer cell dissemination, and "educate" pre-metastatic sites in distant organs, we propose that EVs may also contribute to the disruption of the perineurium barrier and education of the perineural sites into a tumor-promoting microenvironment. It may provide new directions and ideas for further study of PNI pathogenesis in the future. Further, although some research groups have described the involvement of tumor and stroma-derived EVs in the different stages of the metastatic cascade, there is very little information concerning the regulation of tumor cell invasion and metastasis by extracellular vesicles in SACC as well as in PNI.

Of particular note, Galanin is a classic neuropeptide that can function in a variety of physiological processes, such as food intake, nociception, and blood pressure regulation, and it can also act as a growth factor for neurons. Galanin treatment has a tumor-reducing effect in a mouse model of gastrointestinal cancer, and in animal experiments with adenoma formation, galanin appears to be a growth factor that promotes both proliferation and tumor formation (94). In addition, Laminin-5 and insulin-like growth factor-II mRNA binding protein-3 (IMP3) have a good prognostic correlation in various malignancies. Studies have shown that they are also positively expressed in preoperative biopsy specimens of OSCC patients with PNI, implying that preoperative assessment of factors associated with PNI may assist the clinician in the selection of the optimal treatment strategy (95). Nonetheless, whether they can be used as molecular markers of PNI in SACC still needs to be further evaluated.

It's worth mentioning that PNI has been rarely studied in patients with SACC. Emerging evidence for its role as a prognostic factor in SACC is conflicting. Due to the indolent clinical course of SACC, the evaluation of a patient with this malignant tumor is hampered. Furthermore, most previous studies were limited by their small sample size, relatively short follow-up period, mixed pathologies and variable histological sampling of salivary glands, and inadequate reporting of PNI as well (96). Genomic Alterations may also be one of the influencing factors of PNI in SACC. The study found that peripheral nerve invasion was found to be fused with MYB gene with or without copy number changes. MYB-NFIB gene fusion and related GA are associated with ACC peripheral nerve involvement (97). Nonetheless, several studies have found that specific PNI features are indeed closely related to SACC metastasis, locoregional recurrence, long-term survival, and a patient's quality of life (98).

Accordingly, we consider that there are two critical steps in developing strategies for prevention and early therapeutic intervention of PNI: (1) identifying the molecular targets in the microenvironment of perineural niches which are necessary for 
PNI development, and (2) finding specific agents against these molecular targets. Therefore, a deeper investigation of underlying mechanisms of PNI should not only clarify the occurrence, proliferation, invasion, recurrence, and metastasis of SACC, but also provide potential targets for the diagnosis and therapy of neurological disorders and diseases.

In conclusion, multiple processes may result in damage at cancer-neural interfaces. There is reciprocity in these interactions, which confers growth and migration advantages to cancer. An in-depth understanding of the molecular mechanism of PNI is essential for developing therapeutic strategies that not only target cancer cells, but also target neural microenvironments as well.

\section{REFERENCES}

1. Liebig C, Ayala G, Wilks JA, Berger DH, Albo D. Perineural invasion in cancer: a review of the literature. Cancer Am Cancer Soc. (2009) 115:3379-91. doi: $10.1002 /$ cncr.24396

2. Bakst RL, Glastonbury CM, Parvathaneni U, Katabi N, Hu KS, Yom SS. Perineural invasion and perineural tumor spread in head and neck cancer: a critical review. Int J Radiat Oncol Biol Phys. (2018) 103:1109-24. doi: 10.1016/j.ijrobp.2018.12.009

3. Bjorndal K, Krogdahl A, Therkildsen MH, Overgaard J, Johansen J, Kristensen CA, et al. Salivary gland carcinoma in Denmark 1990-2005: a national study of incidence, site and histology. Results of the danish head and neck cancer group (DAHANCA). Oral Oncol. (2011) 47:677-82. doi: 10.1016/j.oraloncology.2011.04.020

4. Cordesmeyer R, Schliephake H, Kauffmann P, Troltzsch M, Laskawi R, Strobel $\mathrm{P}$, et al. Clinical prognostic factors of salivary adenoid cystic carcinoma: a single-center analysis of 61 patients. J Craniomaxillofac Surg. (2017) 45:17847. doi: 10.1016/j.jcms.2017.08.004

5. Coca-Pelaz A, Rodrigo JP, Bradley PJ, Vander PV, Triantafyllou A, Hunt JL, et al. Adenoid cystic carcinoma of the head and neck-an update. Oral Oncol. (2015) 51:652-61. doi: 10.1016/j.oraloncology.2015.04.005

6. Chang CF, Hsieh MY, Chen MK, Chou MC. Adenoid cystic carcinoma of head and neck: a retrospective clinical analysis of a single institution. Auris Nasus Larynx. (2018) 45:831-7. doi: 10.1016/j.anl.2017.10.009

7. Amit M, Na'Ara S, Sharma K, Ramer N, Ramer I, Agbetoba A, et al. Elective neck dissection in patients with head and neck adenoid cystic carcinoma: an international collaborative study. Ann Surg Oncol. (2015) 22:1353-9. doi: 10.1245/s10434-014-4106-7

8. Dillon PM, Chakraborty S, Moskaluk CA, Joshi PJ, Thomas CY. Adenoid cystic carcinoma: a review of recent advances, molecular targets, and clinical trials. Head Neck. (2016) 38:620-7. doi: 10.1002/hed.23925

9. Amit M, Na'Ara S, Trejo-Leider L, Ramer N, Burstein D, Yue M, et al. Defining the surgical margins of adenoid cystic carcinoma and their impact on outcome: an international collaborative study. Head Neck. (2017) 39:1008-14. doi: $10.1002 /$ hed.24740

10. Stelow EB, Bishop JA. Update from the 4th Edition of the world health organization classification of head and neck tumours: tumors of the nasal cavity, paranasal sinuses and skull base. Head Neck Pathol. (2017) 11:3-15. doi: 10.1007/s12105-017-0791-4

11. Luksic I, Suton P, Macan D, Dinjar K. Intraoral adenoid cystic carcinoma: is the presence of perineural invasion associated with the size of the primary tumour, local extension, surgical margins, distant metastases, and outcome? Br J Oral Maxillofac Surg. (2014) 52:214-18. doi: 10.1016/j.bjoms.2013.11.009

12. Singh FM, Mak SY, Bonington SC. Patterns of spread of head and neck adenoid cystic carcinoma. Clin Radiol. (2015) 70:644-53. doi: 10.1016/j.crad.2015.01.013

13. Jang S, Patel PN, Kimple RJ, McCulloch TM. Clinical outcomes and prognostic factors of adenoid cystic carcinoma of the head and neck. Anticancer Res. (2017) 37:3045-52. doi: 10.21873/anticanres.11659

14. Ju J, Li Y, Chai J, Ma C, Ni Q, Shen Z, et al. The role of perineural invasion on head and neck adenoid cystic carcinoma prognosis: a systematic review

\section{AUTHOR CONTRIBUTIONS}

$\mathrm{XYi}$ and $\mathrm{JH}$ conceived the idea of writing the review. XL wrote the review. XYa assisted to edit. CZ and JZ prepared the Tables and Figures. All authors contributed to the article and approved the submitted version.

\section{FUNDING}

This work received support from the Natural Science Foundation of China (Grant No. 81500870) and the Natural Science Foundation of Guangdong Province, China (Grant No. 2016A030313590).

and meta-analysis. Oral Surg Oral Med Oral Pathol Oral Radiol. (2016) 122:691-701. doi: 10.1016/j.oooo.2016.08.008

15. Bakst RL, Wong RJ. Mechanisms of perineural invasion. J Neurol Surg B Skull Base. (2016) 77:96-106. doi: 10.1055/s-0036-1571835

16. Amit M, Na'Ara S, Gil Z. Mechanisms of cancer dissemination along nerves. Nat Rev Cancer. (2016) 16:399-408. doi: 10.1038/nrc.2016.38

17. Gupta A, Veness M, De'Ambrosis B, Selva D, Huilgol SC. Management of squamous cell and basal cell carcinomas of the head and neck with perineural invasion. Australas J Dermatol. (2016) 57:3-13. doi: 10.1111/ajd.12314

18. Yang YH, Liu JB, Gui Y, Lei LL, Zhang SJ. Relationship between autophagy and perineural invasion, clinicopathological features, and prognosis in pancreatic cancer. World J Gastroenterol. (2017) 23:7232-41. doi: 10.3748/wjg.v23.i40.7232

19. Hwang JE, Hong JY, Kim JE, Shim HJ, Bae WK, Hwang EC, et al. Prognostic significance of the concomitant existence of lymphovascular and perineural invasion in locally advanced gastric cancer patients who underwent curative gastrectomy and adjuvant chemotherapy. Jpn J Clin Oncol. (2015) 45:541-6. doi: 10.1093/jjco/hyv031

20. Zareba P, Flavin R, Isikbay M, Rider JR, Gerke TA, Finn S, et al. Perineural invasion and risk of lethal prostate cancer. Cancer Epidemiol Biomarkers Prev. (2017) 26:719-26. doi: 10.1158/1055-9965.EPI-16-0237

21. Kuhn FP, Hullner M, Mader CE, Kastrinidis N, Huber GF, von Schulthess GK, et al. Contrast-enhanced PET/MR imaging versus contrast-enhanced PET/CT in head and neck cancer: how much MR information is needed? J Nucl Med. (2014) 55:551-8. doi: 10.2967/jnumed.113.125443

22. Amit M, Binenbaum Y, Trejo-Leider L, Sharma K, Ramer N, Ramer I, et al. International collaborative validation of intraneural invasion as a prognostic marker in adenoid cystic carcinoma of the head and neck. Head Neck. (2015) 37:1038-45. doi: 10.1002/hed.23710

23. Ihsan Ekin D, Helmut F, Ceyhan GO. Generation and impact of neural invasion in pancreatic cancer. Pancreatic Cancer. (2012) 295-312. doi: $10.5772 / 30117$

24. Peltonen S, Alanne M, Peltonen J. Barriers of the peripheral nerve. Tissue Barriers. (2013) 1:e24956. doi: 10.4161/tisb.24956

25. Pina-Oviedo S, Ortiz-Hidalgo C. The normal and neoplastic perineurium: a review. Adv Anat Pathol. (2008) 15:147-64. doi: 10.1097/PAP.0b013e31816f8519

26. Anderson JM, Van Itallie CM. Physiology and function of the tight junction. Cold Spring Harb Perspect Biol. (2009) 1:a2584. doi: 10.1101/cshperspect.a002584

27. Pummi KP, Aho HJ, Laato MK, Peltonen JT, Peltonen SA. Tight junction proteins and perineurial cells in neurofibromas. J Histochem Cytochem. (2006) 54:53-61. doi: 10.1369/jhc.5A6671.2005

28. Runkle EA, Mu D. Tight junction proteins: from barrier to tumorigenesis. Cancer Lett. (2013) 337:41-48. doi: 10.1016/j.canlet.2013.05.038

29. Anderson JM, Balda MS, Fanning AS. The structure and regulation of tight junctions. Curr Opin Cell Biol. (1993) 5:772-8. doi: 10.1016/0955-0674(93)90024-K

30. Martin TA, Jiang WG. Loss of tight junction barrier function and its role in cancer metastasis. Biochim Biophys Acta. (2009) 1788:872-91. doi: 10.1016/j.bbamem.2008.11.005 
31. Reina MA, Lopez A, Villanueva MC, De Andres JA, Maches F. [The blood-nerve barrier in peripheral nerves]. Rev Esp Anestesiol Reanim. (2003) 50:80-86.

32. Shanthaveerappa TR, Bourne GH. The 'perineural epithelium', a metabolically active, continuous, protoplasmic cell barrier surrounding peripheral nerve fasciculi. J Anat. (1962) 96:527-37.

33. Kanda T. [Blood-nerve barrier: structure and function]. Brain Nerve. (2011) 63:557-69.

34. Demir IE, Boldis A, Pfitzinger PL, Teller S, Brunner E, Klose N, et al. Investigation of schwann cells at neoplastic cell sites before the onset of cancer invasion. J Natl Cancer Inst. (2014) 106:dju184. doi: 10.1093/jnci/dju184

35. Zeng L, Guo Y, Liang J, Chen S, Peng P, Zhang Q, et al. Perineural invasion and TAMs in pancreatic ductal adenocarcinomas: review of the original pathology reports using immunohistochemical enhancement and relationships with clinicopathological features. J Cancer. (2014) 5:754-60. doi: 10.7150/jca. 10238

36. Vonlaufen A, Joshi S, Qu C, Phillips PA, Xu Z, Parker NR, et al. Pancreatic stellate cells: partners in crime with pancreatic cancer cells. Cancer Res. (2008) 68:2085-93. doi: 10.1158/0008-5472.CAN-07-2477

37. Liu ZS, Wang Y, Li Q, Zhang SL, Shi YR. In vitro interaction of human pancreatic cancer cells and rat dorsal root ganglia: a coculture model. Zhonghua Zhong Liu Za Zhi. (2012) 34:259-63. doi: 10.3760/cma.j.issn.0253-3766.2012.04.005

38. Rocco ML, Soligo M, Manni L, Aloe L. Nerve growth factor: early studies and recent clinical trials. Curr Neuropharmacol. (2018) 16:1455-65. doi: 10.2174/1570159X16666180412092859

39. Yamashita N, Kuruvilla R. Neurotrophin signaling endosomes: biogenesis, regulation, and functions. Curr Opin Neurobiol. (2016) 39:139-45. doi: 10.1016/j.conb.2016.06.004

40. Yang X, Martin TA, Jiang WG. Biological influence of brain-derived neurotrophic factor on breast cancer cells. Int J Oncol. (2012) 41:1541-6. doi: $10.3892 /$ ijo.2012.1581

41. Jia S, Wang W, Hu Z, Shan C, Wang L, Wu B, et al. BDNF mediated TrkB activation contributes to the EMT progression and the poor prognosis in human salivary adenoid cystic carcinoma. Oral Oncol. (2015) 51:64-70. doi: 10.1016/j.oraloncology.2014.10.008

42. Fielder GC, Yang TW, Razdan M, Li Y, Lu J, Perry JK, et al. The GDNF family: a role in cancer? Neoplasia. (2018) 20:99-117. doi: 10.1016/j.neo.2017.10.010

43. Zboray K, Mohrherr J, Stiedl P, Pranz K, Wandruszka L, Grabner B, et al. AKT3 drives adenoid cystic carcinoma development in salivary glands. Cancer Med. (2018) 7:445-53. doi: 10.1002/cam4.1293

44. Joseph NM, Mukouyama YS, Mosher JT, Jaegle M, Crone SA, Dormand EL, et al. Neural crest stem cells undergo multilineage differentiation in developing peripheral nerves to generate endoneurial fibroblasts in addition to schwann cells. Development. (2004) 131:5599-612. doi: 10.1242/dev.01429

45. Meng F, Li C, Li W, Gao Z, Guo K, Song S. Interaction between pancreatic cancer cells and tumor-associated macrophages promotes the invasion of pancreatic cancer cells and the differentiation and migration of macrophages. IUBMB Life. (2014) 66:835-46. doi: 10.1002/iub.1336

46. Apte MV, Wilson JS, Lugea A, Pandol SJ. A starring role for stellate cells in the pancreatic cancer microenvironment. Gastroenterology. (2013) 144:1210-19. doi: 10.1053/j.gastro.2012.11.037

47. Ondicova K, Mravec B. Role of nervous system in cancer aetiopathogenesis. Lancet Oncol. (2010) 11:596-601. doi: 10.1016/S1470-2045(09)70337-7

48. Boilly B, Faulkner S, Jobling P, Hondermarck H. Nerve dependence: from regeneration to cancer. Cancer Cell. (2017) 31:342-54. doi: 10.1016/j.ccell.2017.02.005

49. Pundavela J, Roselli S, Faulkner S, Attia J, Scott RJ, Thorne RF, et al. Nerve fibers infiltrate the tumor microenvironment and are associated with nerve growth factor production and lymph node invasion in breast cancer. Mol Oncol. (2015) 9:1626-35. doi: 10.1016/j.molonc.2015. 05.001

50. Jobling P, Pundavela J, Oliveira SM, Roselli S, Walker MM, Hondermarck H. Nerve-cancer cell cross-talk: a novel promoter of tumor progression. Cancer Res. (2015) 75:1777-81. doi: 10.1158/0008-5472.CAN-14-3180

51. Zhao CM, Hayakawa Y, Kodama Y, Muthupalani S, Westphalen CB, Andersen GT, et al. Denervation suppresses gastric tumorigenesis. Sci Transl Med. (2014) 6:115r-250r. doi: 10.1126/scitranslmed.3009569
52. Magnon C, Hall SJ, Lin J, Xue X, Gerber L, Freedland SJ, et al. Autonomic nerve development contributes to prostate cancer progression. Science. (2013) 341:1236361. doi: 10.1126/science. 1236361

53. Couto N, Caja S, Maia J, Strano MM, Costa-Silva B. Exosomes as emerging players in cancer biology. Biochimie. (2018) 155:2-10. doi: 10.1016/j.biochi.2018.03.006

54. Bapat AA, Munoz RM, Von Hoff DD, Han H. Blocking nerve growth factor signaling reduces the neural invasion potential of pancreatic cancer cells. PLoS ONE. (2016) 11:e165586. doi: 10.1371/journal.pone.0165586

55. Ma W, Wang C, Su Y, Tian Y, Zhu H. Expression of nerve growth factor and its receptor, tyrosine kinase receptor A, in rooster testes. Anim Reprod Sci. (2015) 161:40-46. doi: 10.1016/j.anireprosci.2015.08.001

56. Benarroch EE. Brain-derived neurotrophic factor: regulation, effects, and potential clinical relevance. Neurology. (2015) 84:1693-704. doi: 10.1212/WNL.0000000000001507

57. Tanaka K, Okugawa Y, Toiyama Y, Inoue Y, Saigusa S, Kawamura M, et al. Brain-derived neurotrophic factor (BDNF)-induced tropomyosin-related kinase B (Trk B) signaling is a potential therapeutic target for peritoneal carcinomatosis arising from colorectal cancer. PLoS ONE. (2014) 9:e96410. doi: 10.1371/journal.pone.0096410

58. Shan C, Wei J, Hou R, Wu B, Yang Z, Wang L, et al. Schwann cells promote EMT and the schwann-like differentiation of salivary adenoid cystic carcinoma cells via the BDNF/TrkB axis. Oncol Rep. (2016) 35:427-35. doi: $10.3892 /$ or.2015.4366

59. Zhang M, Li ZF, Wang HF, Wang SS, Yu XH, Wu JB, et al. MIF promotes perineural invasion through EMT in salivary adenoid cystic carcinoma. $\mathrm{Mol}$ Carcinog. (2019) 58:898-912. doi: 10.1002/mc.22979

60. Alkhadar H, Macluskey M, White S, Ellis I. Nerve growth factor-induced migration in oral and salivary gland tumour cells utilises the PI3K/Akt signalling pathway: is there a link to perineural invasion? J Oral Pathol Med. (2020) 49:227-34. doi: 10.1111/jop.12979

61. Li H, Yang Z, Wang W, Wang J, Zhang J, Liu J, et al. NT-3/TrkC axis contributes to the perineural invasion and the poor prognosis in human salivary adenoid cystic carcinoma. J Cancer. (2019) 10:6065-73. doi: $10.7150 /$ jca. 33635

62. He S, Chen $\mathrm{CH}$, Chernichenko $\mathrm{N}, \mathrm{He} \mathrm{S}$, Bakst RL, Barajas $\mathrm{F}$, et al. GFRalphal released by nerves enhances cancer cell perineural invasion through GDNF-RET signaling. Proc Natl Acad Sci USA. (2014) 111:E2008-17. doi: 10.1073/pnas.1402944111

63. Zheng SC, Zhang YR, Luo SY, Zhang LP. [The effect of GDNF on matrixdegrading and cell-adhesion during perineural invasion of salivary adenoid cystic carcinoma]. Shanghai Kou Qiang Yi Xue. (2016) 25:212-16.

64. Luo X, Tai WL, Sun L, Pan Z, Xia Z, Chung SK, et al. Crosstalk between astrocytic CXCL12 and microglial CXCR4 contributes to the development of neuropathic pain. Mol Pain. (2016) 12:1744806916636385. doi: $10.1177 / 1744806916636385$

65. Jiang YM, Li G, Sun BC, Zhao XL, Zhou ZK. Study on the relationship between CXCR4 expression and perineural invasion in pancreatic cancer. Asian Pac J Cancer Prev. (2014) 15:4893-6. doi: 10.7314/APJCP.2014.15.12.4893

66. Xu Q, Wang Z, Chen X, Duan W, Lei J, Zong L, et al. Stromalderived factor-1alpha/CXCL12-CXCR4 chemotactic pathway promotes perineural invasion in pancreatic cancer. Oncotarget. (2015) 6:4717-32. doi: 10.18632/oncotarget.3069

67. Klein NT, van Es RJJ, Valstar MH, Smeele LE, Smit LA, Klein GR, et al High CXCR4 expression in adenoid cystic carcinoma of the head and neck is associated with increased risk of locoregional recurrence. J Clin Pathol. (2020) 73:476-82. doi: 10.1136/jclinpath-2019-206273

68. Zhang M, Zhu ZL, Gao XL, Wu JS, Liang XH, Tang YL. Functions of chemokines in the perineural invasion of tumors. Int J Oncol. (2018) 52:136979. doi: 10.3892/ijo.2018.4311

69. Lv CY, Zhou T, Chen W, Yin XD, Yao JH, Zhang YF. Preliminary study correlating CX3CL1/CX3CR1 expression with gastric carcinoma and gastric carcinoma perineural invasion. World J Gastroenterol. (2014) 20:4428-32. doi: 10.3748/wjg.v20.i15.4428

70. Marchesi F, Locatelli M, Solinas G, Erreni M, Allavena P, Mantovani A Role of CX3CR1/CX3CL1 axis in primary and secondary involvement of the nervous system by cancer. J Neuroimmunol. (2010) 224:39-44. doi: 10.1016/j.jneuroim.2010.05.007 
71. Bakst RL, Xiong H, Chen CH, Deborde S, Lyubchik A, Zhou Y, et al. Inflammatory monocytes promote perineural invasion via CCL2-mediated recruitment and cathepsin B expression. Cancer Res. (2017) 77:6400-14. doi: 10.1158/0008-5472.CAN-17-1612

72. He S, He S, Chen CH, Deborde S, Bakst RL, Chernichenko N, et al. The chemokine (CCL2-CCR2) signaling axis mediates perineural invasion. Mol Cancer Res. (2015) 13:380-90. doi: 10.1158/1541-7786.MCR-14-0303

73. Mehta P, Piao X. Adhesion G-protein coupled receptors and extracellular matrix proteins: roles in myelination and glial cell development. Dev Dyn. (2017) 246:275-84. doi: 10.1002/dvdy.24473

74. Jakubowska K, Pryczynicz A, Januszewska J, Sidorkiewicz I, Kemona A, Niewinski A, et al. Expressions of matrix metalloproteinases 2, 7, and 9 in carcinogenesis of pancreatic ductal adenocarcinoma. Dis Markers. (2016) 2016:9895721. doi: 10.1155/2016/9895721

75. Ayala GE, Wheeler TM, Shine HD, Schmelz M, Frolov A, Chakraborty S, et al. In vitro dorsal root ganglia and human prostate cell line interaction: redefining perineural invasion in prostate cancer. Prostate. (2001) 49:213-23. doi: $10.1002 /$ pros.1137

76. Dai H, Li R, Wheeler T, Ozen M, Ittmann M, Anderson M, et al. Enhanced survival in perineural invasion of pancreatic cancer: an in vitro approach. Hum Pathol. (2007) 38:299-307. doi: 10.1016/j.humpath.2006.08.002

77. Deborde S, Omelchenko T, Lyubchik A, Zhou Y, He S, McNamara WF, et al. Schwann cells induce cancer cell dispersion and invasion. J Clin Invest. (2016) 126:1538-54. doi: 10.1172/JCI82658

78. Deborde S, Yu Y, Marcadis A, Chen CH, Fan N, Bakst RL, et al. An in vivo murine sciatic nerve model of perineural invasion. J Vis Exp. (2018) 56857. doi: $10.3791 / 56857$

79. Scanlon CS, Banerjee R, Inglehart RC, Liu M, Russo N, Hariharan A, et al. Galanin modulates the neural niche to favour perineural invasion in head and neck cancer. Nat Commun. (2015) 6:6885. doi: 10.1038/ncomms7885

80. Gu BK, Choi DJ, Park SJ, Kim YJ, Kim CH. 3D bioprinting technologies for tissue engineering applications. Adv Exp Med Biol. (2018) 1078:15-28. doi: 10.1007/978-981-13-0950-2_2

81. Huang TQ, Qu X, Liu J, Chen S. 3D printing of biomimetic microstructures for cancer cell migration. Biomed Microdevices. (2014) 16:127-32. doi: 10.1007/s10544-013-9812-6

82. Fantini V, Bordoni M, Scocozza F, Conti M, Scarian E, Carelli S, et al. Bioink composition and printing parameters for $3 \mathrm{D}$ modeling neural tissue. Cells. (2019) 8:830. doi: 10.3390/cells8080830

83. Saloman JL, Albers KM, Li D, Hartman DJ, Crawford HC, Muha EA, et al. Ablation of sensory neurons in a genetic model of pancreatic ductal adenocarcinoma slows initiation and progression of cancer. Proc Natl Acad Sci USA. (2016) 113:3078-83. doi: 10.1073/pnas.1512603113

84. Mathieu M, Martin-Jaular L, Lavieu G, Thery C. Specificities of secretion and uptake of exosomes and other extracellular vesicles for cell-to-cell communication. Nat Cell Biol. (2019) 21:9-17. doi: 10.1038/s41556-018-0250-9

85. Tkach M, Thery C. Communication by extracellular vesicles: where we are and where we need to go. Cell. (2016) 164:1226-32. doi: 10.1016/j.cell.2016.01.043

86. Tran N. Cancer exosomes as miRNA factories. Trends Cancer. (2016) 2:32931. doi: 10.1016/j.trecan.2016.05.008

87. Taverna S, Giallombardo M, Gil-Bazo I, Carreca AP, Castiglia M, Chacartegui $\mathrm{J}$, et al. Exosomes isolation and characterization in serum is feasible in non-small cell lung cancer patients: critical analysis of evidence and potential role in clinical practice. Oncotarget. (2016) 7:28748-60. doi: 10.18632/oncotarget.7638

88. Zhou W, Fong MY, Min Y, Somlo G, Liu L, Palomares MR, et al. Cancersecreted miR-105 destroys vascular endothelial barriers to promote metastasis. Cancer Cell. (2014) 25:501-15. doi: 10.1016/j.ccr.2014.03.007

89. Hoshino A, Costa-Silva B, Shen TL, Rodrigues G, Hashimoto A, Tesic MM, et al. Tumour exosome integrins determine organotropic metastasis. Nature. (2015) 527:329-35. doi: 10.1038/nature15756

90. Zhang L, Zhang S, Yao J, Lowery FJ, Zhang Q, Huang WC, et al. Microenvironment-induced PTEN loss by exosomal microRNA primes brain metastasis outgrowth. Nature. (2015) 527:100-104. doi: 10.1038/nature15376

91. Becker A, Thakur BK, Weiss JM, Kim HS, Peinado H, Lyden D. Extracellular vesicles in cancer: cell-to-cell mediators of metastasis. Cancer Cell. (2016) 30:836-48. doi: 10.1016/j.ccell.2016.10.009

92. Madeo M, Colbert PL, Vermeer DW, Lucido CT, Cain JT, Vichaya EG, et al. Cancer exosomes induce tumor innervation. Nat Commun. (2018) 9:4215-84. doi: 10.1038/s41467-018-06640-0

93. Hou J, Wang F, Liu X, Song M, Yin X. Tumor-derived exosomes enhance invasion and metastasis of salivary adenoid cystic carcinoma cells. J Oral Pathol Med. (2018) 47:144-51. doi: 10.1111/jop. 12654

94. Rauch I, Kofler B. The galanin system in cancer. Exp Suppl. (2010) 102:223-41. doi: 10.1007/978-3-0346-0228-0_16

95. Tarsitano A, Asioli S, Morandi L, Monti V, Righi A, Morselli LA, et al. Laminin-5 and insulin-like growth factor-II mRNA binding protein-3 (IMP3) expression in preoperative biopsy specimens from oral cancer patients: their role in neural spread risk and survival stratification. J Craniomaxillofac Surg. (2016) 44:1896-902. doi: 10.1016/j.jcms.2016. 07.012

96. Gomez DR, Katabi N, Zhung J, Wolden SL, Zelefsky MJ, Kraus DH, et al. Clinical and pathologic prognostic features in acinic cell carcinoma of the parotid gland. Cancer Am Cancer Soc. (2009) 115:2128-137. doi: $10.1002 /$ cncr.24259

97. Joseph I, Rooban T, Elizabeth J, Rao UK, Ranganathan K. Genomic alterations landscape in adenoid cystic carcinoma of head and neck. J Orofac Sci. (2009) 11:73-78. doi: 10.4103/jofs.jofs_40_19

98. Amit M, Eran A, Billan S, Fridman E, Na'Ara S, Charas T, et al. Perineural spread in noncutaneous head and neck cancer: new insights into an old problem. J Neurol Surg B Skull Base. (2016) 77:86-95. doi: 10.1055/s-0036-1571834

Conflict of Interest: The authors declare that the research was conducted in the absence of any commercial or financial relationships that could be construed as a potential conflict of interest.

Copyright (c) 2020 Liu, Yang, Zhan, Zhang, Hou and Yin. This is an open-access article distributed under the terms of the Creative Commons Attribution License (CC $B Y)$. The use, distribution or reproduction in other forums is permitted, provided the original author(s) and the copyright owner(s) are credited and that the original publication in this journal is cited, in accordance with accepted academic practice. No use, distribution or reproduction is permitted which does not comply with these terms. 